are incapable of delivering effective stimuli to patients with high seizure thresholds. Furthermore, as Pippard commented, individual preference for different anaesthetics would make stimulus quantification for individual patients more complicated should such a policy be introduced in this country.

Anaesthetic ignorance of the problems inherent in using propofol in ECT is the most likely explanation for its frequent use. In turn this can be seen as a consequence of psychiatrists neglecting ECT and of their poor liaison with anaesthetists. We suggest that closer liaison between the two professions is added to Pippard's list of recommendations, and furthermore stress that at present propofol should be avoided, where possible, in ECT anaesthesia.

American Psychiatric Association (1990) Task Force on ECT: The Practice of ECT: Recommendations for Treatment, Training and Privileging. Washington DC: APA.

DWYER, R., MCCAUGHeY, J., LA Very, J., el al (1988) Comparison of propofol and methohexitone as anaesthetic agents for electroconvulsive therapy. Anaesthesia, 43, 459-462.

Lowson S., GeNT, J. P. \& GoOdChILD, C. S. (1990) Anticonvulsant properties of propofol and thiopentone: comparison using two tests in laboratory mice. British Journal of Anaesthesia, 64, 59-63.

Simpson, K. H., Halsall, P. J., Carr, C. M. E., el al (1988) Propofol reduces seizure duration in patients having anaesthesia for electroconvulsive therapy. British Journal of Anaesthesia, 61, 343-344.

Department of Psychiatry

Peter M. Haddad

SUSAN M. BENBOW

Manchester Royal Infirmary

Oxford Road

Manchester M139BX

\section{Ventricular size in schizophrenia}

SIR: Van Horn \& McManus's meta-analysis of ventricular enlargement in schizophrenia (Journal, May 1992, 160, 687-697) provides a valuable review of the evidence, but I would like to take issue with their conclusions. They point out that all the studies have shown a wide variance around the means - in other words there is a very considerable overlap between the scores of 'controls' and of 'schizophrenics'. This is true even of the important study of discordant identical twins by Suddath et al (1990), which they mention in their text but do not include in their table.

The conclusion should be not that "schizophrenics indubitably have larger ventricles than controls", but that "while some schizophrenics have larger ventricles than controls, most schizophrenics' VBRs are within the normal range." The difference is important, because the issue is not one of specificity of diagnosis but of inferences about aetiology. The simple statement 'schizophrenics have larger ventricles than controls' should be answered 'No' in any MRC Psych MCQ question.

Suddath, R. L. Christison, G. W., Torrey, E. F., et al (1990) Anatomical abnormalities in the brains of monozygotic twins discordant for schizophrenia. New England Journal of Medicine. 322, 789-794.

\section{Sydenham Hill}

J. L. T. BIRLEY

\section{London SE26 6LW}

\section{Hemisphere dysfunction in psychiatric disorders}

SIR: Dr Cutting's interesting article on the role of hemisphere dysfunction in psychiatric disorders (Journal, May 1992, 160, 583-588), although generally informative and balanced, did appear to set up poor Flor-Henry as an Aunt Sally. His arguments, especially in his later writings, are more sophisticated than one would gather from this article. In particular, he makes clear distinctions between the consequences of actively discharging lesions compared with those of areas of passive neuronal destruction, and he uses the concept of reciprocal inhibition especially between corresponding areas in opposite hemispheres. Both concepts have their origin in the writings of Hughlings Jackson. If used, Dr Cutting's anti Flor-Henry argument from the evidence provided by the results of temporal lobectomy turns out to be in fact a pro Flor-Henry one.

Moreover, some of the earliest work on the distinction between right and left hemisphere depressions was carried out by Fromm-Auch who was working in very close association with Flor-Henry at the time.

Department of Psychiatry

C. M. H. NuNN

Royal South Hants Hospital

Brintons Terrace

Southampton SO9 4PE

SIR: In the review by Cutting of the role of hemispheric cerebral dysfunction in the genesis of psychiatric disorders (Journal, May 1992, 160, 583-588) he suggests that disorders of the left cerebral hemisphere are related to an increased incidence of severe depressive disorder. In order to address this question I have recently analysed the results from 41 consecutive patients admitted with subarachnoid haemorrhage to compare the site of the subarachnoid haemorrhage with the development of depression, something that has not previously been done in this group of patients. These patients were assessed as part of a study investigating the incidence of depression in acutely ill medical patients (Silverstone, 